\title{
LOS DESAFÍOS EN DERECHOS HUMANOS EN EL CHILE ACTUAL
}

\author{
Lorena Fries Monleón
}




\section{LORENA FRIES MONLEÓN}

Abogada, Master en Derecho Internacional de los Derechos Humanos de la Universidad de Oxford y abogada por la Corte Suprema de Chile. Con 25 años de experiencia, ha desarrollado programas pioneros en materia de derechos humanos tanto con miembros de las Fuerzas Armadas y de la Policía y jueces y funcionarios públicos en América del Sur. Ha coordinado la presentación de informes sombra ante el Sistema de Derechos Humanos de Naciones Unidas, e informes regionales ante el Sistema Interamericano de Derechos Humanos. Asimismo, ha participado en procesos de negociación de tratados de derechos humanos y justicia como representante de la sociedad civil. Autora de varias publicaciones y artículos en el ámbito de los derechos humanos de las mujeres. Es profesora de postgrado en el Diplomado Derechos Humanos de las Mujeres: Teoría y práctica en el Centro de Derechos Humanos de la Facultad de Derecho de la Universidad de Chile. Fundadora de Corporación Humanas, organización no gubernamental con sede en Chile, Colombia y Ecuador. Actualmente se desempeña como Directora del INDH (Instituto Nacional de los Derechos Humanos), órgano público autónomo. 


\section{LOS DESAFÍOS EN DERECHOS HUMANOS EN EL CHILE ACTUAL}

Este artículo tiene por objeto reflexionar en torno a los problemas que la democracia chilena actual muestra para la incorporación de una concepción integral de derechos humanos, que sustente la noción de democracia participativa o de ciudadanía. Se trata de comprender en clave de derechos humanos los límites de la democracia actual a partir del recorrido que ha tenido el discurso y la práctica de los derechos humanos en Chile e identificar los nudos teóricos, políticos, institucionales y culturales que atentan contra su inclusión como eje vertebrador de una sociedad diversa y democrática.

\section{INTRODUCCIÓN}

Desde su formulación inicial en 1948, los derechos humanos han tenido un desarrollo vertiginoso y se han instalado como uno de los elementos centrales de las democracias modernas. Dicho desarrollo se expresa desde dos aristas distintas -el derecho constitucional y el derecho internacional de los derechos humanos-, en la constante y dinámica ampliación de la gama de derechos reconocidos como tales, en el fortalecimiento de mecanismos que los protegen y en la apropiación que de los mismos han hecho los(as) ciudadanos(as) y organizaciones que los promueven y los defienden.

El corpus normativo actual de los derechos humanos ha transitado en los niveles domésticos, desde una concepción liberal y restringida del Estado de Derecho -por tanto, con énfasis en las libertades y derechos políticos- hacia una que ubica la justicia social y los derechos económicos, sociales y culturales, y el reconocimiento de las identidades subordinadas, como parte de este derrotero. No en vano hemos pasado de contar con tres instrumentos fundantes de los derechos humanos a ocho, los que actualmente constituyen el núcleo duro de tratados en el campo internacional ${ }^{1}$. En el ámbito nacional, ese proceso, aun cuando más lento, ha sido parte de los procesos de reforma

1. Declaración Universal de Derechos Humanos; Pacto Internacional de Naciones Unidas de Derechos Civiles y Políticos; Pacto Internacional de Naciones Unidas de Derechos Económicos, Sociales y Culturales; Convención contra la Tortura y otras Penas, Tratos crueles, inhumanos o degradantes; Convención de Naciones Unidas sobre Eliminación de todas las Formas de Discriminación hacia las Mujeres; Convención de Naciones Unidas sobre Eliminación de todas las Formas de Discriminación Racial; Convención de Naciones Unidas sobre los Derechos del Niño(a); Convención de Naciones Unidas sobre la Protección de todos los Trabajadores Migratorios y sus Familiares; Convención de Naciones Unidas sobre los Derechos de las Personas con Discapacidad, además de la Convención Americana de Derechos Humanos y la Declaración de Derechos y Deberes del Hombre, también del sistema americano. (N. de la A.) 
constitucional, llegando a su máxima expresión regional en el caso de Colombia, Bolivia y Ecuador y sus nuevas cartas constitucionales. ${ }^{2}$

Desde el punto de vista de los mecanismos que se han establecido para su protección, otro tanto ha ocurrido. En efecto, a nivel internacional se cuenta con procedimientos que habilitan a los(as) ciudadanos(as) de los Estados Parte para reclamar internacionalmente acerca de aquellos derechos que el Estado no ha podido o querido proteger, ya sea en su forma jurisdiccional, como lo son la Corte Interamericana de Derechos Humanos y la Corte Penal Internacional, ya sea a través de resoluciones y recomendaciones de órganos que supervisan el cumplimiento de estos tratados ${ }^{3}$, que van generando un sedimento fecundo para la cristalización en nuevos tratados o convenciones. En el plano nacional, los bloques constitucionales, que tienen un conjunto de tratados y la obligatoriedad interna de garantía y protección que ello genera para los poderes del Estado, así como las acciones o tutelas de derechos fundamentales, constituyen avances que se han visto favorecidos desde los movimientos neo-constitucionalistas progresistas. Otro tanto ocurre con la creación de instituciones públicas y autónomas que con distintos nombres cumplen labores de protección y promoción en prácticamente todos los países de América del Sur.

La historia de los derechos humanos es también la de la ciudadanía y su ampliación. La abolición de los privilegios y la igualdad como principio jurídico y político han permitido desde la Revolución francesa el desarrollo de un proceso histórico de inclusión de sectores inicialmente no considerados, parte de la "comunidad entre iguales". La abolición de la esclavitud, el sufragismo, el movimiento por los derechos civiles, el reconocimiento de los pueblos indígenas y de las diversidades sexuales, son todas expresiones de un proceso que no ha cesado y que sigue modelando nuestros horizontes normativos y de lucha política. Este legado democrático ha sido en buena parte, pues, el que ha permitido construir imaginarios y posibilidades que alimentan hoy nuevas luchas por el reconocimiento, garantía y protección de los derechos humanos. Así, la Convención sobre Eliminación de todas las Formas de Discriminación hacia las Mujeres, la Convención sobre la Eliminación de todas las Formas de Discriminación Racial, la Convención de los Derechos de los Niños, Niñas y Adolescentes, y la Convención sobre los Derechos de las Personas con Discapacidad, entre otras, expresan la cristalización e inclusión de sectores de la sociedad al estatus de titulares de derechos humanos.

No obstante, su formulación o reconocimiento, su grado real de protección y eficacia, así como los énfasis políticos que se dan a unos sobre otros responden al contexto político, institucional y cultural de cada sociedad. En efecto, las sociedades postdictadura y postconflicto en América Latina, han debido lidiar, en distintos grados de

2. 2009 en Bolivia y 2008 y 2010 en Ecuador. (N. de la A.)

3. Cada una de las convenciones crea su órgano de supervisión de cumplimiento. Estos comités tienen como primera función dotar de sentido y alcance a los derechos que reconoce el tratado en particular, evaluar el grado de cumplimiento del Estado Parte en relación al tratado, investigar las situaciones particulares que son puestas bajo su conocimiento y/o investigar las graves situaciones de violación a los derechos del tratado referido que pudieran acaecer dentro de un Estado Parte. (N. de la A.) 
complejidad, con las deudas en derechos humanos del pasado a la vez que instalar y consolidar instituciones democráticas. El equilibrio entre estos dos objetivos ha estado dado, entre otras cosas, por el tipo de salida política, la fuerza que mantienen quienes sustentaban los regímenes dictatoriales o las fuerzas en conflicto en la fase de transición, la legitimidad de los poderes judiciales para procesar las violaciones de derechos humanos, así como las herramientas jurídicas de las que dispusieron para hacerlo.

Por otra parte, los Estados postconflicto o postdictadura han pasado, con mayor o menor rapidez, de una etapa de democracia fusionada con la idea liberal restrictiva del Estado de Derecho a una de redefinición y potenciación tanto de dicho Estado de Derecho -Estado Social de Derechos- como de la democracia, tal cual lo refleja el debate existente entre democracia participativa, representativa y de ciudadanía. A la base de estos procesos se encuentran los derechos humanos y la participación.

El avenimiento de la democracia en Chile restituyó el orden jurídico político relegando a un segundo momento la participación ciudadana como dinamizadora y legitimadora de la democracia. En particular, la democracia chilena se forjó después de 1990 sobre la base de afiatar la gobernabilidad por sobre la participación y, con ello, por el desplazamiento de un elemento clave para la democracia y los derechos humanos. En efecto, la participación ciudadana, más allá de su componente electoral -que es el mínimo- es la gran deuda con la democracia chilena, puesto que abre el proyecto democrático a "...redistribuir el poder para garantizar a los individuos el ejercicio de sus derechos" ${ }^{\prime \prime}$. En el contexto global actual ello necesariamente implica la inclusión de una gama de derechos que incorpora necesariamente los derechos económicos, sociales y culturales.

Ya el discurso sobre la integralidad de los derechos humanos posterior al fin de la guerra fría ${ }^{5}$ afirmaba este camino, al explicitar la indivisibilidad e interdependencia de los derechos humanos, a la vez que deconstruía el discurso liberal del sujeto universal, dando lugar a la expresión de múltiples identidades que requerían del reconocimiento de su diferencia y la superación de la discriminación en el campo de los derechos humanos. El impacto en Chile de este discurso es reciente y obedece tanto al agotamiento de una forma de Estado de Derecho y de democracia como al trabajo que durante estas décadas han sostenido las organizaciones no gubernamentales de derechos humanos, las que progresivamente empiezan a actuar en sintonía con las demandas de la ciudadanía. Y es que estas demandas, aún difusas desde la lógica de los derechos humanos, expresan tanto la necesidad por mayor y mejor participación como la incorporación de temas que hacen parte de la agenda global de derechos humanos: medioambiente, pueblos indígenas, mujeres, diversidades sexuales y de género, acceso a condiciones materiales para una vida digna, etc.

4. PNUD y OEA, Nuestra Democracia (Sección de Obras de Sociología), Fondo de Cultura Económica, 2010, pág. 3.

5. Conferencia Mundial de Naciones Unidas sobre Derechos Humanos, Viena, 1993. 


\section{PRINCIPALES TENSIONES EN EL CAMPO DE LOS DERECHOS HUMANOS}

\section{La tensión entre el pasado y el presente/futuro}

En Chile, la historia de los derechos humanos se releva a partir de las violaciones de que fueron objeto miles de chilenos y chilenas durante la dictadura militar. La noción de los derechos humanos está, por tanto, ineludiblemente ligada a la experiencia de violación, fundamentalmente de derechos civiles y políticos. El hecho que ese fuera el carácter principal de los derechos vulnerados y que así quedara fijado en la memoria colectiva ha ido en desmedro y desconocimiento de otros derechos, como lo demuestra una encuesta realizada durante los primero meses de 2011, en la que un 80,33\% de los(as) entrevistados(as) coincidía que durante dicho período se habían vulnerado los derechos básicos, y a su vez, y en un porcentaje que disminuye significativamente, desconocían la especificidad de otros derechos como los de igualdad y no discriminación, o los derechos económicos, sociales y culturales.

Estos datos se explican, en gran medida, por un modelo de transición que no reactualizó el discurso de los derechos humanos y que en sus primeros veinte años más bien los ligó en términos de política pública a la obligación de verdad y reparación. Es en este marco que se realizan los primeros avances normativos e institucionales en materia de derechos humanos; la reforma constitucional al Art. 5, que incorpora los tratados internacionales como parte del tramado normativo chileno, la creación de las Comisiones de $\operatorname{Verdad}^{6}$ y el Programa de Derechos Humanos del Ministerio del Interior ${ }^{7}$. A esto hay que sumar el conjunto de políticas adoptadas por los gobiernos de los últimos veinte años, distribuidas en su ejecución entre el Ministerio de Educación, Salud e Interior, y un conjunto de medidas que dicen relación con la obligación de reparación y con las recomendaciones que emanaron de las comisiones de verdad.

Así, es reciente la cristalización de una mirada más amplia sobre los derechos humanos y con ello las posibilidades institucionales que trae aparejadas. La Oficina de Derechos Humanos de la Corporación de Asistencia Judicial ${ }^{8}$ y la reciente creación del Instituto Nacional de Derechos Humanos ${ }^{9}$ reflejan la vinculación entre el pasado y sus violaciones a los derechos humanos y el presente con "nuevos temas" de derechos

6. Desde 1990 en adelante se han creado en Chile tres comisiones de verdad: La Comisión de Verdad y Reconciliación o Comisión Rettig (1990), la Comisión Nacional de Prisión Política y Tortura o Comisión Valech (2003), y la Comisión Asesora para la calificación de detenidos desaparecidos, ejecutados políticos y víctimas de prisión política y tortura (2009). Las tres han tenido como mandato el esclarecimiento de los hechos constitutivos de violaciones a los derechos humanos (desaparición forzada, ejecuciones arbitrarias, prisión política y tortura), y reconocer a las victimas su calidad de tales para efectos de acceso a políticas de reparación. (N. de la A.)

7. El Programa Continuidad de la Ley 19.123 se creó por Decreto Supremo No 1.005 del Ministerio del Interior, de 1997, bajo la dependencia de la Subsecretaría del Interior y reformado por la ley 20.405 del 10 de diciembre de 2009. (N. de la A.)

8. Creada en 1992 para representar a las víctimas de las atrocidades durante la dictadura. Se ha ampliado a temas relacionados con tortura y violencia policial en democracia. (N. de la A.)

9. Ley 20.405, que crea el Instituto Nacional de Derechos Humanos. (N. de la A.) 
humanos, a lo que se suma el anuncio de creación de una Subsecretaría de Derechos Humanos al alero del Ministerio de Justicia.

A pesar de ello, el vínculo -desde el punto de vista del discurso- entre pasado y presente no termina de reactualizarse, subsistiendo comunidades de derechos humanos que no encuentran las narrativas que les permitan una interlocución mutua. Tanto desde las organizaciones vinculadas a la defensa histórica de los derechos como desde las actuales, han sido escasos los puntos de encuentro. Valga destacar el trabajo de la Comisión Ética contra la Tortura que ha denunciado los actos de este tipo en la actualidad, o el caso de Corporación Humanas, la cual, siendo una ONG reciente, ha promovido una mirada de género sobre la tortura durante el régimen de Pinochet y judicializado los primeros casos de violencia sexual como tortura en el caso de mujeres víctimas de prisión política.

No obstante, y principalmente desde el Estado -aunque también desde la sociedad civil organizada-, esta no ha sido la mirada y se requiere de acciones que contribuyan a reactualizar los temas de derechos humanos del pasado en problemas del presente. Aun cuando el contexto difiere radicalmente del pasado, temas como la tortura, la violencia policial, la libertad de expresión y/o de reunión, pueden ser traídos al presente desde la experiencia y conocimiento acumulados en dicho pasado. Al revés, los temas relacionados con la discriminación por razones de género, de etnia e incluso etarias pueden dar una nueva dimensión al relato sobre las violaciones del pasado, afianzar en la actualidad la necesidad de superarla y, ambas, dotar de continuidad histórica a los derechos humanos.

\section{La tensión entre lo universal y lo particular}

El carácter universal de los derechos humanos es una afirmación que debe ser aclarada porque convoca a múltiples explicaciones. Por lo pronto, la idea de universalidad involucra aspectos temporales, territoriales y culturales. Respecto de la dimensión temporal de la universalidad, esta, de alguna manera, ha sido abordada en el punto anterior.

Respecto de la dimensión territorial -esto es, que los derechos humanos se aplican en cualquier parte del mundo- dice relación con el grado de adhesión de los Estados que hacen parte del sistema universal de protección de los derechos humanos. La otra dimensión es la discursiva, que dice relación con a quiénes, dónde y cuándo rigen o se aplican los derechos humanos. En el primer caso, el número de Estados Parte de un tratado y convención da cuenta del consenso que este suscita, y por tanto de la fuerza moral -además de la jurídica- que tiene para imponerse. Así, un tratado de derechos humanos que no concita a su ratificación a los Estados o que no consigue la adhesión de Estados de todos los continentes pierde fuerza en su aplicación. En la actualidad, los principales tratados de derechos humanos se encuentran ratificados por la mayoría de los Estados, incluido Chile, que a partir de 1990 se reinsertó en la comunidad internacional, poniéndose al día en estas materias. Si bien esta mirada sobre la universalidad fue problemática durante la dictadura, ha sido superada con la plena incorporación del 
Estado a los principales foros multilaterales de derechos humanos y con la suscripción y ratificación de la mayoría de los tratados existentes en esta materia. Chile contribuye de esta manera a fortalecer una dimensión de la universalidad que supera la crítica de que estos serían el producto del consenso entre países ricos y de Occidente.

La universalidad como componente discursivo cultural de los derechos humanos ha sido criticada en particular por el sesgo liberal de sus orígenes y las restricciones de que es portadora. Esta crítica ha permeado de manera significativa las concepciones actuales de derechos humanos. Así, más que una formulación abstracta y por tanto ahistórica, la universalidad se ha transformado en un punto de llegada, esto es, en procesos históricos de lucha por el reconocimiento de derechos y por esa vía de la apropiación de discursos y prácticas que van ampliando la ciudadanía y los ámbitos de regulación. En efecto, la historia de los derechos humanos es una historia de democratización permanente, que desde la particularidad construye sentidos y valores comunes presentes en todas las culturas, como lo son la dignidad y el respeto por el(la) otro(a). Las luchas de los movimientos indígenas, de mujeres o de las diversidades sexuales, por nombrar los que tienen presencia en Chile, dan buena cuenta de este proceso en el que, junto con consignar su diferencia y a veces ausencia del registro de los derechos, fortalecen la idea de universalidad de los derechos humanos.

En este contexto de universalización y no de universalidad, el sujeto universal pasa de un sujeto abstracto a uno contextualizado, que tiene por tanto género, edad, etnia, etc., y un contexto en el que vive, es decir un conjunto de vínculos y de relaciones sociales, económicas y culturales. En efecto el sujeto universal solo escondía bajo su pretensión de universal y abstracto su sesgo androcéntrico, heterosexual y racista.

Los procesos de democratización que se venían dando antes del 73 y que ampliaban las posibilidades de ser en la sociedad chilena se vieron violentamente truncados, instalándose una concepción única de convivencia que reforzó todas las jerarquías sociales de género, etnia y clase, excluyéndolas del discurso de derechos. Luego, ya en democracia se dividen las posibilidades institucionales de los(as) ciudadanos(as). Por una parte se reconocen deudas históricas con las mujeres y los pueblos indígenas, con los jóvenes, las personas con discapacidad y las de la tercera edad. En todos estos casos se crea algún tipo de institucionalidad pública y se procesan desde allí las demandas posibles en el contexto de transición democrática. Para aquellas demandas que no caben en el modelo de transición hay mucha salida, puesto que los canales de participación de la ciudadanía se reducen al campo electoral, que a su vez tiene una dinámica que hace difícil su procesamiento. En la práctica se apuesta a que sean los partidos políticos los capaces de asumir dichas demandas, los que sin embargo están más pendientes del rédito electoral que pueden obtener que de fijar líneas programáticas e idearios políticos que devuelvan a la ciudadanía una mirada integrada de país.

En particular los temas de derechos que dicen relación con la autonomía, sea de pueblos o de grupos de personas histórica o contingentemente discriminadas, son los que han sufrido el impacto de la transición. Los procesos de universalización de derechos humanos en Chile se enfrentan al problema del reconocimiento de la diferencia y la autonomía, es decir a una matriz autoritaria -en el sentido de restricción de la libertad 
y asignación jerarquizada de lugares sociales para los(as) diferentes- que no ha cedido y más bien se refuerza en el modelo institucional y democrático chileno. Particularmente, en el caso de las mujeres, de los pueblos indígenas y de las diversidades sexuales, la postergación en el reconocimiento de sus derechos civiles y políticos es evidente; las mujeres aún son discriminadas en el ámbito patrimonial del matrimonio, gozan de una autonomía limitada sobre sus cuerpos; no se ha reconocido tampoco el carácter plurinacional del Estado chileno y menos aun algún grado de autonomía para los pueblos originarios que habitan en el territorio. Recién en el 2011, después de más de veinte años de democracia, se inicia un debate público sobre los derechos civiles de la población gay, lésbico y trans, con altos niveles de resistencia. Cabe decir, sin embargo, que la instalación que han tenido estos temas como parte del debate público -incluidos redes y TIC- ha demostrado ser la metodología ciudadana requerida. En efecto, genera adhesión y participación ciudadana, y con ello el temor y el irrespeto al otro que se expresa en prejuicios, estereotipos y una gran violencia simbólica -y lamentablemente también material-cede frente a argumentos e información que son los que deben concurrir a la formación de una opinión pública democrática.

\section{La tensión entre lo local y lo global}

Los derechos humanos nacen como límite al poder del Estado pero a la vez son instituidos por el propio poder político, esto es, generando (auto)obligaciones para su garantía y respeto. No obstante, tener una dimensión de soberanía nacional en tanto el Estado se compromete garantizar dichos derechos también tienen una dimensión internacional en la medida que son los propios Estados los que han contribuido con su voluntad a crear un sistema de alerta y supervisión de cumplimiento de los tratados que reconocen y protegen derechos. Es más, el sistema internacional de protección de los derechos humanos incorpora a los ciudadanos de los Estados que se hacen parte de la comunidad internacional como sujetos en el campo del derecho internacional de los derechos humanos.

La coherencia entre los derechos humanos a nivel nacional y a nivel internacional está dada en una parte por su "positivización" y por otra por el mecanismo o sistema de incorporación o recepción de la normativa internacional a nivel nacional. Como se dijera antes, esto se ha facilitado en Chile de manera general a través del Art. 5, el que de todas maneras ha resultado insuficiente si se considera la falta de invocación de dichas normas por parte de abogados(as) y jueces. Por ello, en la experiencia comparada, la vía de la réplica de los derechos reconocidos a nivel internacional en las constituciones políticas e instituciones como el bloque de constitucionalidad o el precedente judicial que considera tanto sentencias internacionales como otro tipo de resoluciones internacionales, han sido formas de unificar dos sistemas jurídicos que en la tradición de Estado Nacional no era del todo bienvenidos.

La globalización ha contribuido a la internacionalización de los derechos humanos, dotándolos de un contexto que, por la vía del desarrollo de las comunicaciones y por 
la vía de la economía, han traspasado las fronteras nacionales. Esta ha tenido impacto también en la comprensión de lo que es hoy la ciudadanía. Nadie podría negar que en Chile los avances en materia de derechos de las mujeres han sido impulsados también por la sintonía entre el movimiento de mujeres a nivel global y aquel que se expresa a nivel nacional. Ha tomado tiempo a los ciudadanos tomar conciencia de la necesidad de transitar permanentemente en estas dos dimensiones para poder avanzar en materia de derechos, en particular en aquellas sociedades en las que los estándares de derechos fundamentales son más bajos que los estándares a nivel internacional.

Desde el punto de vista de los contenidos o formulaciones de derechos humanos, la globalización ha contribuido a relevar la importancia de aquellos derechos que preocupan a las comunidades globales, puesto que las impactan en tanto tales. Es el caso claramente del medioambiente y de algunos derechos básicos, como el de alimentación o el derecho al agua, y de derechos aún en debate, como el derecho a la democracia o al desarrollo. Con menos desarrollo que los otros ámbitos de derechos, no hay porque pensar que estos procesos de involucramiento del interés ciudadano global van a detenerse, pues más bien pareciera que avanzan, aunque lentamente, hacia su cristalización como derechos en el ámbito internacional.

En Chile tanto en la dimensión institucional como la que proviene desde la ciudadana hay desafíos evidentes. Por una parte, la positivización de los derechos fundamentales obedece a un período histórico -dictadura- que hoy no representa las necesidades de la ciudadanía ni las posibilidades reales de protección que debe dar el Estado en esta materia. No existe el bloque de constitucionalidad, salvo en relación con el Convenio 169 de la OIT, el cual, por la vía de fallos del Tribunal Constitucional, se ha convertido en uno de los instrumentos autoejecutables a nivel nacional. No obstante, la jurisprudencia en general, tanto respecto de este convenio como de otros, ha sido poco uniforme.

Chile tiene una mirada reductiva de los derechos humanos que, o no cubre todos los aspectos del contenido de dichos derechos, o no los protege de manera eficaz a la luz del sentido y alcance que le dan los órganos internacionales competentes en esta materia. En particular, hay déficit en cuanto a los temas de igualdad y reconocimiento de la diferencia y de derechos sociales. Es precisamente en estos dos ámbitos en los que la disonancia entre lo nacional y lo internacional se expresa más nítidamente. Por una parte, el Estado chileno manifestó su voluntad de contribuir al fortalecimiento del sistema de protección internacional de los derechos humanos y, por otra, no fue capaz de actualizar a nivel nacional muchos de estos avances. La ciudadanía global y en tiempo real se nutre de las comunicaciones para sintonizar la demanda y la reacción frente a hechos que los conmocionan. En Chile la sociedad civil organizada ha logrado entender la necesidad de transitar entre lo nacional y lo internacional, y viceversa -y de manera recurrente-, con el fin de ampliar las posibilidades de presión democrática hacia el Estado y sus poderes, generándose algunas respuestas por parte de los poderes del Estado involucrados (medidas administrativas o legislativas). La ciudadanía, más allá de los sectores organizados se mantuvo bastante al margen de estos procesos en razón de la ausencia de canales de participación que en última instancia son los que permiten encauzarla. Solo después de 20 años, y a raíz de las movilizaciones multitudinarias que han tenido lugar en el primer 
semestre de 2011, cabe pensar que hay una demanda por articular de manera distinta la relación entre democracia, ciudadanía y derechos humanos.

Para terminar, cabe señalar que Chile y su democracia se enfrentan a sendos desafíos para adecuarse a los tiempos actuales. Sin duda, la participación ciudadana en versiones más amplias que las conocidas hasta ahora es condición para ello, como también lo es la generación de mecanismos institucionales de promoción y protección más eficaces, así como mecanismos y procedimientos más efectivos para la incorporación y recepción del derecho internacional de los derechos humanos en el plano nacional. La democracia del siglo XXI debe ser capaz de dar respuesta a las complejas necesidades nacionales y globales que afectan a los(as) ciudadanos(as). Los derechos humanos son un catálogo abierto que se reactualiza constantemente y la democracia debe contemplar los canales que permitan dicha dinámica.

A final de cuentas, la democracia conjuga en su esencia la idea del derecho a tener derechos.

\section{REFERENCIAS BIBLIOGRÁFICAS}

De Asís, R., Las paradojas de los derechos fundamentales como límites al poder. Madrid: Instituto Bartolomé de las Casas, Universidad Carlos III de Madrid, 2000.

Menke C. y Pollmann A., Filosofía de los Derechos Humanos, Hamburgo: Editorial Herder, 2007.

PNUD, OEA, Nuestra Democracia (Sección de Obras de Sociología), Fondo de Cultura Económica, 2010 